\title{
Erratum zu: Gesellschaftliche Probleme und Handlungsfelder der Politik
}

\section{Erratum zu:}

\section{Kapitel 17 in: W. Rudzio, Das politische System der Bundesrepublik Deutschland, https://doi.org/10.1007/978-3-658-22724-1_17}

Der Inhalt von Tabelle 1 wurde korrigiert.

\begin{tabular}{|c|c|c|c|c|}
\hline \multicolumn{5}{|c|}{ Tab. 1: Bevölkerung und Zuwanderer im Vergleich 2016} \\
\hline \multicolumn{5}{|l|}{ In $\%$ der beiden Gruppen } \\
\hline 1) Schulabschluss & $\begin{array}{l}\text { Ohne } \\
\text { Schulabschluss }\end{array}$ & $\begin{array}{l}\text { Hauptschule } \\
\text { a) }\end{array}$ & Realschule a) & $\begin{array}{l}\text { Abitur/ } \\
\text { Ähnliches a) }\end{array}$ \\
\hline Gesamtbevölkerung > 15 J. & 8,2 & 34,2 & 24,7 & 33,5 \\
\hline Mit Migrationshintergrund $>15 \mathrm{~J}$. & 19,2 & 34,3 & 24,6 & 39,8 \\
\hline 2) Berufliche Bildungsabschlüsse & Ohne Abschluss b) & Lehre a) & Fachschule a) & $\begin{array}{l}\text { Diplom/ } \\
\text { Ähnliches a) }\end{array}$ \\
\hline Gesamtbevölkerung $>15 \mathrm{~J}$. & 26,0 & 64,6 & 11,9 & 17,5 \\
\hline Mit Migrationshintergrund $>15 \mathrm{~J}$. & 46,6 & 59,4 & 9,0 & 19,3 \\
\hline 3) Überwiegend Lebensunterhalt durch c) & Berufstätigkeit & Hartz IV & Angehörige & Rente/Pension \\
\hline Einwohner ohne Migrationshintergrund & 80,0 & 55,0 & 67,6 & 89,6 \\
\hline mit Migrationshintergrund & 20,0 & 45,0 & 32,4 & 10,4 \\
\hline \multicolumn{5}{|c|}{$\begin{array}{l}\text { Die Zahlen addieren sich nicht stets zu Hundert, da kleinere Kategorien nicht mit aufgenommen sind. Zum Ver- } \\
\text { gleich: Der Bevölkerungsanteil mit Migrationshintergrund beträgt 22,5\% der Gesamtbevölkerung. } \\
\text { a) In Prozent derer mit Abschluss. } \\
\text { b) Darunter bei der Gesamtbevölkerung } 34 \% \text { in Ausbildung, bei Migrationshintergrund } 27 \% \text { in Ausbildung. } \\
\text { c) Hier in Prozent der jeweiligen Lebensunterhalts-Gruppe. } \\
\text { Quelle: Statistisches Jahrbuch Deutschland und Internationales } 2017 \text {, Wiesbaden } 2017, \text { S. } 42,84,86 \text {. }\end{array}$} \\
\hline
\end{tabular}

Die korrigierte Version des Kapitels ist verfügbar unter https://doi.org/10.1007/978-3-658-22724-1_17

(C) Springer Fachmedien Wiesbaden GmbH, ein Teil von Springer Nature 2019 